\title{
Sciendo \\ MICROBIOLOGICAL RISK ASSESSMENT AND BIOPROCESS ENGINEERING
}

doi:10.2478/mape-2018-0030

Date of submission of the article to the Editor: 04/2018

Date of acceptance of the article by the Editor: 07/2018

MAPE 2018, volume 1, issue 1, pp. 233-239

Prof. dr hab. Grażyna Płaza

Silesian Technical University, Poland

Varenyam Achal

Guangdong Technion-Israel Institute of Technology, China

Deepika Kumari

School of Ecological and Environmental Sciences, East China Normal University, China

Tongji University, China

\begin{abstract}
The Europe 2020 strategy (European Commission, 2010) calls a bioeconomy as a key element for smart and green growth in Europe. The development of a greener and more resourceefficient economy gives rise to new technologies and materials, which in turn may result in increased exposure to biological agents or combinations of different potentially harmful factors. For example, the expanding recycling industry employs an increasing number of workers which have to face various health problems (pulmonary, gastrointestinal and skin problems) as a result of exposure to biological agents such as airborne microorganisms. However, specific numbers for occupational diseases in this sector are still lacking. There are various workplaces and professional activities especially from the green industry for which exposure to microbiological agents occur unexpectedly and in an uncontrolled way. The issue of uncontrolled microbial exposure there is for example in waste treatment and for retrofitting activities, both growing sectors of employment in a greening society. As a result of the problem in the green industrial sector, there is a need to develop tools for risk assessment and prevention measures. In order to be able to develop suitable risk management strategies, a further development of detection and identification methods for biological agents is needed to cover the whole spectrum of microorganisms. the present paper focuses on the microbiological risk assessment in the context of the development of new and safe industrial products and processes of green industry (bioindustry and bioprocessing).
\end{abstract}

Key words: green industry, risk assessment, MRA, microorganisms, bioprocess, engineering

\section{INTRODUCTION}

The 1990's in particular have seen growing government and industry commitment towards developing an internationally-accepted methodology for assessing the importance of microbiological risk. Serious and well-published outbreaks of foodborne disease in the USA and Europe have highlighted the need to improve the identification of new hazards connected with develop of industrial biological processes. In recent years, industrial biological processes have been increasingly used in the chemical industry, from pharmaceutical to food industries or energy production (EU-OSHA, 2011; Wolniak and Skotnicka-Zasadzień, 2014; Wandzich and Płaza, 2017). The increase in the number of bioprocess facilities associated to the scaleup to industrial production, as well as to the industrial implementation of innovative processes and technologies, is generating in emerging risk (Moreno et al., 2016; Midor and Jąderko, 2017).

A bioprocess is a process that use biological agents to obtain products or complete a chemical transformation (Moreno et al., 2016). The risk related to bioprocesses is called biohazard or 
biological hazard. The main health effects of exposure to biological agents are infections caused by bacteria, viruses or parasites, allergies triggered by, for example, mould, organic dusts, enzymes or mites and poisoning or toxic effects due to exposure to microorganisms, in part or in whole, or their metabolites (EU-OSHA, 2010). Worldwide, it is estimated that more than 300000 workers die every year as a result of diseases caused by viral, bacterial or animal-related biological hazards (Reinert et al., 2007).

Microorganisms are small organisms that require microscopic tools for visualisation, and include bacteria, fungi (e.g. yeast and mould), viruses and some parasites. Many microorganisms are harmless to humans and serve useful functions, but others can cause serious harm. These disease-causing microorganisms are called pathogens and if allowed to multiply in cosmetic products, they can infect the human body and cause serious harm to consumers. Some microorganisms, called opportunistic pathogens, do not normally cause disease in healthy people but may cause disease in those with weakened immune systems (Buchanan et al., 2000).

Microbiological durability depends on product composition, content of preservatives, manufacturing hygiene, packaging, transport and storage. The ability of microorganisms to grow and reproduce in bioproducts is well known (Havelaar et al., 2008; Hebisch and Linsel, 2012). Water is essential for microbial growth and water-based products often have a limited durability, as they are sensitive to microbial growth. Raw materials can contribute to a significant level of microbial contamination to the finished product. Testing of raw materials before use, especially those of natural origin is important. The specifications of the raw materials must include microbiological purity. Water is a raw material, and the most common ingredient. Water must be tested continuously for microbial growth. It might be necessary to sterilize deionized water to obtain a sufficient purity. Many other conditions of production may influence the contamination during manufacturing, such as contaminated areas, insufficient manufacturing hygiene, personnel hygiene and insufficient preservation (Pietrangeli, 2008). Now, the biological hazards are the one of the most important hazard in the green workplaces and bioengineering production (Fig. 1).

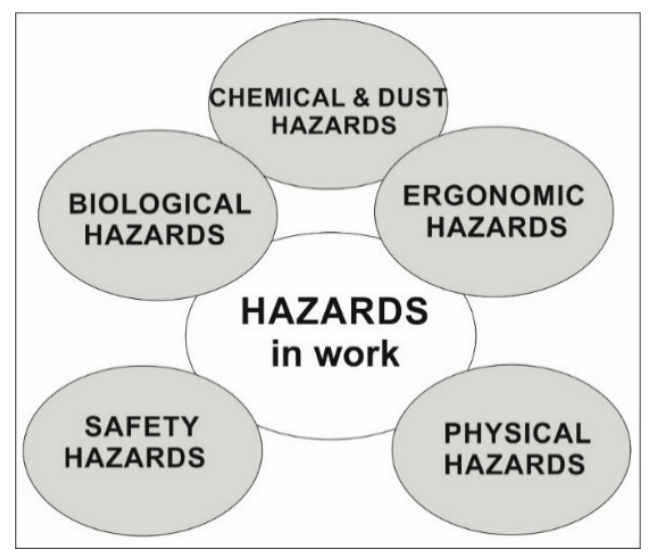

Fig. 1. Various types of hazards in the workplaces and in the production

A global shift towards a greener and more sustainable economy exposes workers to traditional hazards however, a combination of old risks within new settings and conditions is expected. The current speed of expansion in green jobs will lead to a skills gap and a reliance on a large number of inexperienced and/or underskilled workers who will be handling and interacting with new or unfamiliar technologies. As with any new and developing technology, workers in 'green jobs' will also be exposed to new hazards, which probably have not been previously identified. These "'green" challenges can be met only by developing safe working processes together with workplaces that fully exploit new processes and technologies. Industrial biotechnology enables the development of promising energy-efficient, sustainable processes for producing 
food, chemicals and pharmaceuticals. These processes have the advantage of relying principally on low-energy, atmospheric pressure systems and use far fewer synthetic chemicals as raw materials than the equivalent chemical processes. The corresponding risks may therefore be diminished. In industrial biotechnology the unknown issues are primarily related to exposure to biological agents, (microorganisms and their components), which can be harmful to workers' health, provoking, for example, infections or allergies. For this purpose, the methods of risk quantification have to be develop (Havelaar et al., 2008). The one of the approach to identify the new hazards in the green technologies is a microbial risk assessment (MRA), a valuable tool for organizations tasked with understanding, reducing, and preventing risks presented by hazardous microorganisms (biological hazard) (CCFRA, 2007).

The present paper focuses on the microbiological risk assessment in the context of the development of new and safe industrial products and processes of green industry (bioindustry and bioprocessing).

\section{BIOLOGICAL AGENTS}

"Biological agents" are defined as "microorganisms" including those which have been genetically modified, cell cultures and human endoparasites, which may be able to provoke any infection, allergy or toxicity" (Notermans and Barendsz, 2002). However, 'microorganism' refers to 'a microbiological entity, cellular or non-cellular, capable of replication or of transferring genetic material' (European Directive 2000/54/EC). The European Directive 2000/54/CE has the goal to protect workers from risks for their safety and their health from exposure to biological agents at work. The Directive applies to food industry, agriculture, healthcare plants, all kind of laboratories, wastewater treatment, and waste management. Microorganisms are present in various workplaces. Workplace exposure to biological agents can be direct or indirect as an unintended result of work processes. Direct exposure may, for example, occur as a result of the use of micro-organisms in the food industry or in a microbiology laboratory, whereas indirect exposure occurs during activities such as waste treatment or agriculture.

Workplace exposure to biological agents can be direct or indirect as an unintended result of work processes. Direct exposure may occur during the use of microorganisms in, for example, the food industry or research laboratories, whereas indirect exposure occurs during activities such as waste treatment, retrofitting and agricultural activities and in the healthcare sector where antimicrobial resistant microorganisms can pose a serious threat. Workers in the rapidly growing waste management and recycling industry face various health problems including pulmonary, skin and gastrointestinal problems owing to the exposure to bioaerosols that may contain not only microorganisms but also endotoxins, sensitising substances and volatile organic compounds. They can also be present in biotechnology installations.

\section{MICROBIOLOGICAL RISK ASSESSMENT (MRA)}

Microbiological Risk Assessment (MRA) is a structured and scientific process for evaluating the risk posed by microorganisms and up to now it has been recognized as an essential approach in food safety management, together with risk management and risk communication. The Codex Alimentarious Commission (CAC) developed principles and guidelines to define the nature of, and provide a methodology for, assessing the risks to human health from pathogens in foods (Codex Alimentarius Commission,1999). The CAC defines microbiological risk assessment as a scientifically-based process involving four key steps which are designed to produce a risk estimate: (1) hazard identification, (2) hazard characterization, (3) exposure assessment, and (4) risk characterization.

These steps have been defined by WHO/FAO and bearing in mind that no only food processing plants have the massive resources of microorganisms. The purpose of hazard identification is to identify the microorganism(s) of concern that may be present in the process. The hazards of concern may come from a variety of sources including: raw materials, methods 
of production and use of the product. Moreno et al. (2016) proposed that the creation of a checklist is the first step toward the creation of a full methodology aimed at hazard identification of bioprocesses. The checklist is divided into two sections: the first is a process specification section (engineering process) and in the second section, some questions related to management process hazard analysis (PAH).

When the specific pathogens of concern is identified, the next step is hazard characterization. This should be conducted for each pathogen identified. In its simplest terms, hazard characterization is an assessment of the pathogen and the nature of the problems it can cause. In order to develop a true understanding of the character of the hazard the answers for the following questions should be done: what is the disease caused by the pathogen?, what are the symptoms and how long before their onset?, what are the range and likelihood of adverse outcomes, e.g. death?, what is the minimum dose required to produce symptoms? and who are the main at risk groups in the population? (CCPS, 2011). In the previous two steps the likely hazards of concern was identified and characterized in terms of the dose and response. When conducting a microbiological risk assessment the next step is exposure assessment. The aim of exposure assessment is to determine the level of the microorganism (or toxin) likely to be present in the product during its using. Here a number of potential paths or routes of contamination and the impact of various processing steps on microbiological levels should be taken into account. The following are important: the microbiology of the raw material, initial contamination levels of raw materials, the effects of production, processing, handling, etc. on the levels of pathogens in the final product, sanitation standards in your processing plant, potential for recontamination after a specific control point, characteristics of the food being produced, product usage and instructions. The Risk Assessment Model gives a structured approach to the all the exposure paths.

The microbiological risk assessment is still a relatively new and emerging discipline especially in the context of the development of new bioindustry sectors. As presented by Moreno et al. (2016) many countries defined their own biological risk assessment method.

The CAC has placed risk assessment as the first step within a broader framework of risk analysis consisting of: risk assessment, risk communication and risk management. The risk assessment, as its name suggests, provides a formal, validated and transparent estimate of the level of risk. Such assessments provide a basis for making decisions, setting priorities and adopting appropriate procedures for various types of industries including food and various sectors of bioindustry safety management (Gembalska-Kwiecień, 2017).

Microbial risk assessment (MRA) is a relatively new tool for a better means of ensuring not only the production of safety food but now also for the production of different kind of bioproducts - products of bioprocess engineering (bioindustry). The use of risk assessment ensures that control of food and bioproducts production safety is based on a logical and scientific approach to the problem involved. In practice, elements of MRA have been utilized for many years, although they were not formally recognized as such. For example, at the end of the nineteenth hazard identification was used in the description of the botulism in humans. Next, in 1943 the Clostridium perfringens and in the 1950s Bacillus cereus were recognized as foodborne pathogens. Data for hazard identification have been obtained from the analysis of many incidents of foodborne disease.

During the long time, the underlying causes of foodborne illness were unknown. However, the situation was changed when Louis Pasteur showed that certain bacteria were either associated with food spoilage or caused specific diseases. Based on Pasteur's findings, commercial heat treatment of wine was first introduced in 1867 to destroy any undesirable microorganisms, and the process was described as "pasteurization". Another important development occurred in Germany, when Robert Koch introduced a method of growing microorganisms in pure culture and, with colleagues, first isolated the Vibrio cholerae bacterium in 1884, during the a worldwide pandemic. Over the next years, huge 
microorganisms have been isolated and identified in laboratories over the world. In the Table 1 the important steps in the development of microbial safety system are presented.

Good Manufacturing Practices (GMP) - one of the first quality assurance systems developed by the food industry, as a supplement to end-product testing. GMP has been used for many years to ensure the microbiological safety and quality of food, and it provides a framework for hygienic food production. And now this system is related to the bioprocess engineering. The establishment of GMP is the outcome of long practical experience, and it includes attention to environmental conditions in the plants integrated chemical engineering and biotechnology, e.g. requirement for plant layout, hygienic design of equipment, and control of operational procedures. GMP should ensure that products, whilst not necessarily sterile, contain no harmful organisms and that the microbiological population is of a low and stable order and/or declines over the product lifetime. GMP includes specific cleaning procedures to keep all apparatus and materials appropriately clean. Procedures also include microbiological control of raw materials, bulk and finished products, packaging material, personnel, equipment and preparation and storage rooms.

Table 1

Important steps in the development of microbial safety system

\begin{tabular}{|c|c|}
\hline Time & Activity \\
\hline Distant past & Use of "prohibition" principle to protect special groups within society against foodborne illnesses \\
\hline 1900 to present & Microbiological examination of food \\
\hline 1922 & Introduction of process performance criteria by Esty \& Meyer for canned, low-acid food products \\
\hline $1930-1960$ & $\begin{array}{l}\text { Use of risk assessment (for different pathogenic organisms) in setting process performance } \\
\text { criteria for heat pasteurization of milk }\end{array}$ \\
\hline 1960 & Introduction of Good Manufacturing Practices (GMP) \\
\hline 1971 & Introduction of formal Hazard Analysis Critical Point system (HACCP) \\
\hline ca 1972 & Start of predictive modelling of bacterial growth in food \\
\hline 1995 - & Introduction and adaptation of formal quantitative risk analysis to various purposes \\
\hline
\end{tabular}

Source: (Notermans and Barendsz, 2000).

The GMP concept has been extended by introducing the Hazard Analysis and Critical Control Point system (HACCP). The HACCP is a systematic approach to the identification, assessment and control of hazards. It aims to identify problems before they occur and establish measures for their control at stages in production that are critical to ensuring the safety of product (Wolniak et al., 2017). The HACCP was developed by Barendsz and Untermann in the 1960s. The concept arose from a collaboration between the Pillsbury Company, the US Army Natick Research and Development Laboratories and the US National Aeronautics and Space Administration. The original purpose was to establish a system of safe food production for use in human space travel. At that time, more attention was given to controlling the processes involved first in food production and handling but now this approach is introduced to various sectors of bioindustry. Three principles are involved in this concept: (i) hazard identification and characterization, (ii) identification of critical control points (CCPs), (iii) monitoring of the CCPs. The seven principles of the HACCP are determined: (1) conduct a hazard analysis, (2) determine the critical control points (CCPs), (3) establish critical limit(s), (4) establish a system to monitor control of the CCP, (5) establish corrective actions, (6) establish verification procedures, (7) establish documentation and record keeping (Notermans and Barendsz, 2000).

In the Fig. 2 the scheme of the safety systems for chemicals and for microbiological agents in bioprocesses is presented.

The bioprocesses safety control is increasingly dependent on a more prospective approach, involving the application of GMP and HACCP principles and risk assessment (CCPS, 2011). 


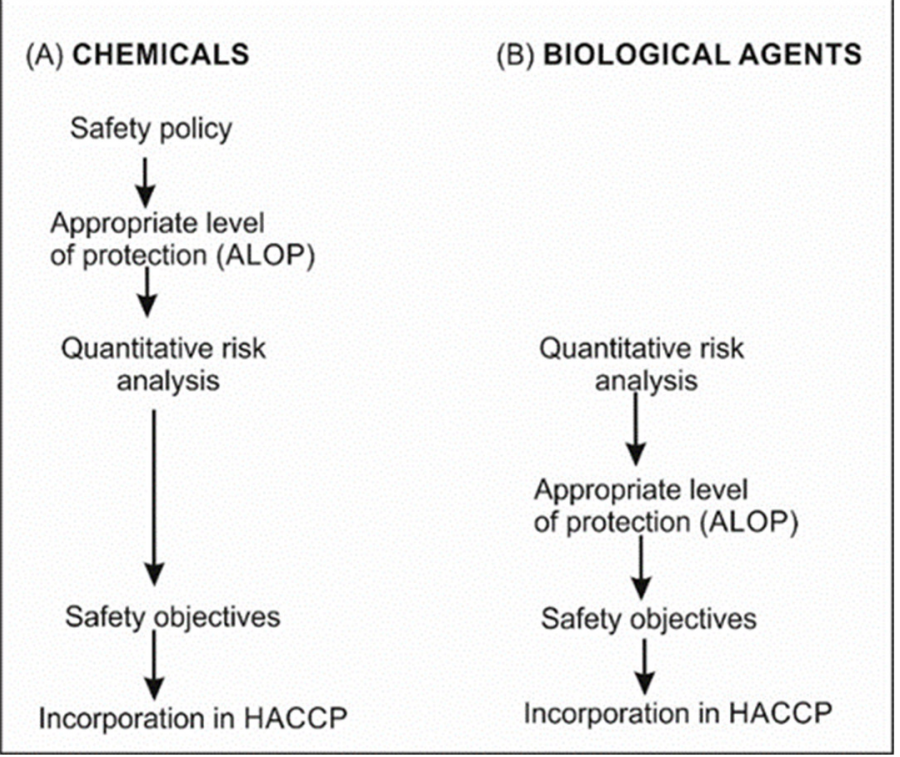

Fig. 2. The differences between current safety system for chemicals and microbiological agents Source: (Notermans and Barendsz, 2000).

\section{CONCLUSIONS}

The drive for change towards creating a green economy in the EU requires a need for the research on the identification the new risks in development of green industry and green jobs. The process of identifying hazards in the design (i.e. prevention through design) and developmental phases, and managing and controlling hazards should be part of the deployment of emerging energy and green technologies.

The development of industrial biological processes, new technologies such as biotechnology establishes new or increased exposures to biological agents. In all working conditions, workers are exposed, to varying extents, to different kinds of hazards including chemical, physical and biological (mixed exposures are a reality in workplaces). Workplaces, technologies and work are effected by the complex hazard, and knowledge of multifactorial exposure should be developed in the field of the sampling and analytical methods and direct-measuring techniques for microorganisms to identify the whole spectrum for microbiological agents in new and various sectors of green industry (EU-OSH, 2013).

\section{ACKNOWLEDGEMENTS}

This paper is connected with the project entitled "Development of intelligent production methods as well as work and life environments in the context of production engineering challenges" (no 13/030/BK_18/0039) financed by the Ministry of Science and Higher Education, Poland.

\section{REFERENCES}

Buchanan, R.L., Smith, J.L. and Long, W. (2000). Microbial risk assessment: dose-response relations and risk characterization. International Journal of Food Microbiology, 58 (1), pp. 159-172.

CAC (Codex Alimentarius Commission) (1999). Principles and guidelines for the conduct of microbiological risk assessment. Document CAC/GL-30. FAO, Rome.

CCFRA (2007). Industrial microbiological risk assessment: A practical guide (second edition). CCFRA Guideline 28

CCPS (2011). Guidelines for process safety in bioprocess manufacturing facilities.

EU- OSHA (European Agency for Safety and Health at Work) (2010). ESENER — managing safety and health at work. Available at: http://osha.europa.eu/en/publications/reports/esener1_osh_management

EU-OSH Priorities for occupational safety and health research in Europe: 2013-2020 (2013). Publications Office of the European Union. ISBN: 978-92-9240-068-2 doi: 10.2802/25457. 
EU-OSHA (European Agency for Safety and Health at Work) (2011). Foresight of new and emerging risks to occupational safety and health associated with new technologies in green jobs by 2020 , phase II - key technologies. Available at: https://osha.europa.eu/en/publications/reports/foresight-green-jobs-key-technologies

European Commission (2010). EUROPE 2020. A strategy for smart, sustainable and inclusive growth. Brussels COM(2010).

European Parliament (2000). Directive 2000/54/EC.

Gembalska-Kwiecień, A. (2017). Development of an Innovative Methodology Supporting Project Risk Management in the Manufacturing Company of the Automotive Industry. In: Proceedings of the 6th International Conference on Operations Research and Enterprise Systems. ICORES 2017, Porto, Portugal vol. 1, pp. 265-271.

Havelaar, A.H., Evers, E.G. and Nauta, M.J. (2008). Challenges of quantitative microbial risk assessment at EU level. Trends in Food Science and Technology, 19, pp. S22-S29.

Hebisch, R. and Linsel, G. (2012). Workers' exposure to hazardous substances and biological agents in recycling enterprises. Gefahrstoffe - Reinhaltung der Luft, 72 (4), pp. 163-169.

Midor, K. and Jąderko, K. (2017). Analysis of the energy potential of municipal solid waste for the thermal treatment technology development in Poland. International Conference on Advances in Energy Systems and Environmental Engineering - ASEE17, 2-5 July 2017 DOI: $10.1051 /$ e3sconf/20172200116.

Moreno, V.C., Giacomini, E. and Cozzani, V. (2016). Identification of major accident hazards in industrial biological processes. Chemical Engineering Transactions, 48 (3), pp. 679-684.

Notermans, S. and Barendsz, A. W. (2002). The evaluation of microbiological risk assessment. In: Microbiological risk assessment in food processing. Brown M., Stringer M. (eds). CRC Press LLC Woodhead Publishing Limited, Cambridge England, pp. 5-43. ISBN: 1855735857.

Pietrangeli, B. (2008). Biological risks in workplaces: Priorities for OSH research for risk assessment. Prevention Today, 4 (1), pp. 57-68.

Reinert, D., Flaspöler, E., Hauke, A. and Brun, E. (2007). Identification of emerging occupational safety and health risks. Safety Science Monitor, 11 (3), pp. 16-24.

Wandzich, D.E. and Płaza, G.A. (2017). New and emerging risks associated with „Green” workplaces. Workplace Health \& Safety 65 (10), pp. 493-500.

Wolniak, R. and Skotnicka-Zasadzień, B. (2014). The use of value stream mapping to introduction of organizational innovation in industry. Metalurgija, 53 (4), pp. 709-712.

Wolniak, R., Skotnicka-Zasadzień, B. and Zasadzień, M. (2017). Application of the theory of constraints for continuous improvement of a production process - case study, $3^{\text {rd }}$ International Conference on Social, Education and Management Engineering (SEME 2017), Shanghai, pp. 169-173. 